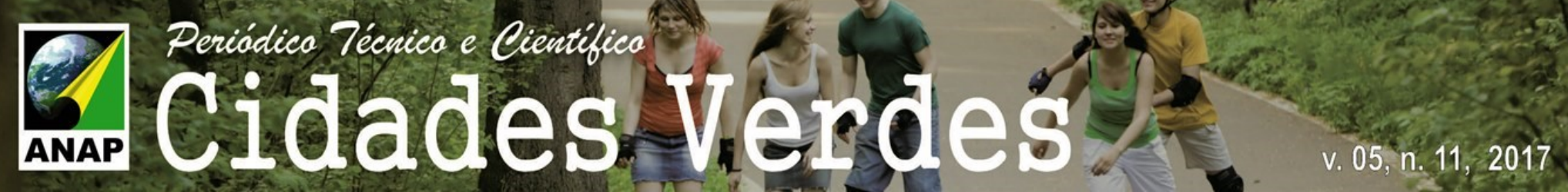

\title{
Praça Sílvio Romero: Infraestrutura e Percepção de frequentadores em São Paulo - SP
}

Silvio Romero Square: Infrastructure and Perception of the regulars. Sao Paulo-SP

Plaza de Sílvio Romero: Infraestructura y la percepción de los clientes habituales. Sao Paulo - SP
Rosana Clara de Jesus Barros Bióloga, UNINOVE, Brasil ro_smarcos@yahoo.com.br

Ana Paula do Nascimento Lamano Ferreira Professora Doutora, GeAS-UNINOVE, Brasil apbnasci@yahoo.com.br 


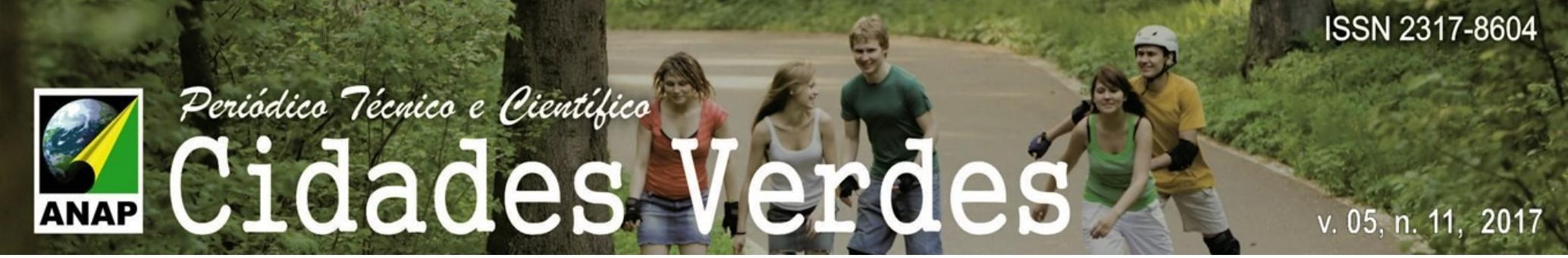

\section{RESUMO}

A percepção da população sobre uma praça interfere diretamente na preservação e conservação da mesma. Desta forma, o presente artigo objetivou levantar quanti-qualitativamente os equipamentos, infraestrutura e a percepção de frequentadores da Praça Sílvio Romero, situada no bairro do Tatuapé na Cidade de São Paulo. A coleta de informações obedeceu aos critérios de modelo de De Angelis et al. (2004). A Praça Silvio Romero apresenta boa infraestrutura para seus frequentadores tanto em quantidade de equipamentos quanto em qualidade. $O$ espaço possui 148 bancos conservados, 25 lixeiras, 2 telefones públicos, 1 ponto de ônibus, 1 ponto de táxi, 14 quiosques de alimentação e estes podem variar sua quantidade conforme o dia. Os resultados da percepção ambiental dos frequentadores em relação à praça mostram que $57 \%$ concordam que a responsabilidade no cuidado da praça é da Prefeitura e $96 \%$ concordam que a praça contribui para diminuir a poluição do ar. A percepção dos frequentadores é muito importante para que os gestores públicos possam melhorar o planejamento e manutenção das praças.

PALAVRAS-CHAVE: Áreas Verdes Urbana. Percepção Ambiental. Praças Públicas.

\section{ABSTRACT}

The perception of the population about a square interferes directly in the preservation and conservation of the same. In this way, the present article aimed to quantify qualitatively the equipments, infrastructure and the perception of regulars of Praça Sílvio Romero, located in the district of Tatuapé in the City of São Paulo. The data collection obeyed the model criteria of De Angelis et al. (2004). The Silvio Romero Square presents good infrastructure for its customers, both in quantity and in quality. The space has 148 conserved banks, 25 dumps, 2 public telephones, 1 bus stop, 1 taxi stand, 14 food kiosks and these can vary their amount according to the day. The results of the environmental perception of the visitors regarding the square show that $57 \%$ agree that the responsibility in the care of the square is of the City Hall and $96 \%$ agree that the square contributes to decrease the air pollution. The perception of regulars is very important so that the public managers can improve the planning and maintenance of the squares.

KEY WORDS: Urban Green Areas. Environmental Perception. Public squares.

\section{RESUMEN}

La percepción de la población sobre una plaza interfiere directamente en la preservación y conservación de la misma. De esta forma, el presente artículo objetivó levantar cuantitativamente los equipos, infraestructura y la percepción de frecuentadores de la Plaza Sílvio Romero, situada en el barrio del Tatuapé en la Ciudad de São Paulo. La recolección de información obedeció a los criterios de modelo de De Angelis et al. (2004). La Plaza Silvio Romero presenta una buena infraestructura para sus asistentes tanto en cantidad de equipamientos como en calidad. El espacio tiene 148 bancos conservados, 25 basureros, 2 teléfonos públicos, 1 punto de autobús, 1 punto de taxi, 14 quioscos de alimentación y estos pueden variar su cantidad según el día. Los resultados de la percepción ambiental de los asistentes en relación a la plaza muestran que el $57 \%$ concuerda que la responsabilidad en el cuidado de la plaza es del Ayuntamiento y el $96 \%$ concuerda que la plaza contribuye a disminuir la contaminación del aire. La percepción de los asistentes es muy importante para que los gestores públicos puedan mejorar la planificación y el mantenimiento de las plazas.

PALABRAS CLAVE: Áreas Verdes Urbanas. Percepción Ambiental. Plazas Públicas. 
Cada indivíduo constrói ao longo de suas experiências de vida, crenças e valores uma percepção referente ao local que habita e de seus componentes. Dessa forma, as percepções sobre os espaços ao nosso entorno são resultados individuais, ou seja, alguns ambientes despertam sensações positivas em algumas pessoas e outros negativos. Assim os estímulos sensoriais são muitos e estão relacionados ao que decidimos prestar atenção e valorizar (TUAN, 2012).

O ser humano atualmente tem valorizado ambientes que trazem melhorias para a qualidade de vida (PEREIRA et al., 2012). Ricklefs (2011), cita a urgência em se ter um ambiente com qualidade, sem poluição sem rejeitos e visualiza na ecologia humana um norte, um desafio para que a humanidade aprenda e ensine às futuras gerações a ter uma relação mais assertiva, sustentável com toda área verde (praça, parque, jardim), comunidades, ecossistemas, com toda a biosfera.

Lima e Ferreira (2015) mencionam que as áreas verdes presentes nas cidades são importantes para que o ser humano tenha contato com o meio ambiente devido a isto, estas áreas têm que oferecer à população que a frequenta condições que favoreçam as expectativas esperadas. Quando as expectativas da população estão dentro da esperada, as pessoas desenvolvem com o local uma relação mais estreita. Isto implica em melhor qualidade de vida para o indivíduo como melhor cuidado com o espaço público.

Segundo Costa e Colesanti (2011), pensar em áreas verdes significa refletir na qualidade do ambiente e na qualidade de vida para a sociedade. O ambiente é indissociável do ser humano. Fernandes et al. (2004) cita que a questão ambiental é um quesito prioritário para a sociedade e que este conceito vem se tornando cada vez mais urgente no âmbito mundial. Pensar sobre meio ambiente significa pensar na consciência do ser humano e esta passa pelo crivo da educação.

Morero et al. (2007) afirma que, é preciso ter praças e áreas verdes, e estas devem ser prioridade e estar pautadas na necessidade do ser humano ter direito ao lazer, qualidade de vida e por conseguinte a saúde. E não simplesmente depender do planejamento e implantação destas áreas visando à população de maior renda que reside nestes locais. Desse modo, o conceito de praças passa a ter um amplo significado, de acordo com o contexto em que a palavra praça é empregada.

De acordo com Houaiss (2008), praça é uma área urbanizada frequentemente ajardinada, para descanso e lazer, mas também pode ser um lugar aberto onde se compra ou se vende, um mercado, uma feira ou uma área comercial e financeira de uma cidade. O conceito de praça é bem amplo como já citado anteriormente e pode vir a mudar de acordo com a cidade, país e a cultura local.

No Brasil, normalmente o conceito de praça está associada com áreas verdes, contudo, ainda há exceções, visto que em algumas localidades as praças dispõem somente de equipamentos de infraestrutura sem vegetação propriamente dita (BENCHIMOL et al., 2017). Entretanto, para Robba e Macedo (2002) as praças públicas são espaços verdes onde há uma interação entre a população e o meio natural. 


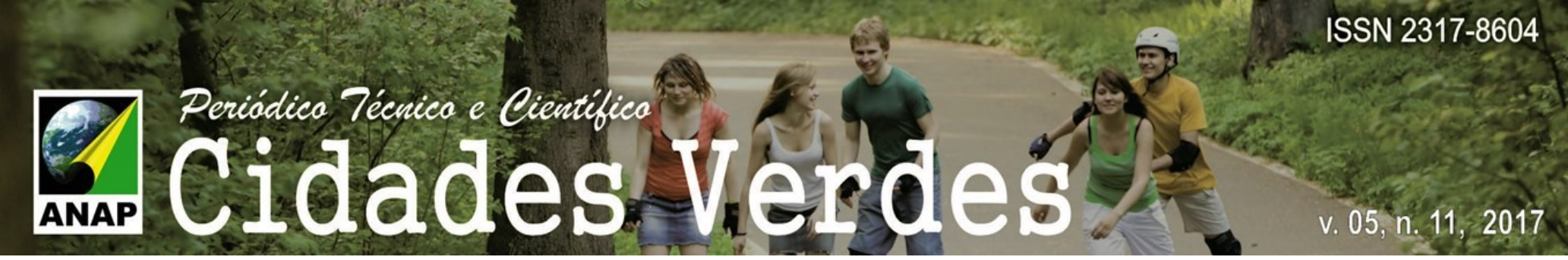

As praças desempenham função social, pois estão relacionadas à saúde daqueles que a frequentam. Por isso, a predominância de áreas verdes nas praças pode promover bem-estar e melhorias na qualidade de vida dos frequentadores desses espaços. Nesse contexto, Lima et al. (2015) destacam que as áreas verdes presentes nas cidades são importantes para que o ser humano tenha contato com o meio ambiente. Diante dessa premissa, este trabalho teve por objetivo investigar a percepção ambiental de frequentadores da Praça Silvio Romero, além de realizar um levantamento da infraestrutura desse espaço. Cabe mencionar que a Praça Sílvio Romero foi escolhida como área de estudo por apresentar valor histórico, cultural e ambiental à região onde está implantada.

\section{METODOLOGIA}

\section{ÁREA DE ESTUDO}

A Praça Sílvio Romero está localizada no distrito do Tatuapé, que é administrado pela Subprefeitura da Mooca, na região Leste da Cidade de São Paulo. O bairro do Tatuapé possui 91.672 habitantes e dispõem de $8,20 \mathrm{Km}^{2}$ de área (IBGE, 2010). Na figura 1 é possível observar a localização dos bairros administrados pela subprefeitura da Mooca, em especial o Tatuapé, no qual está implantada a Praça Sílvio Romero.

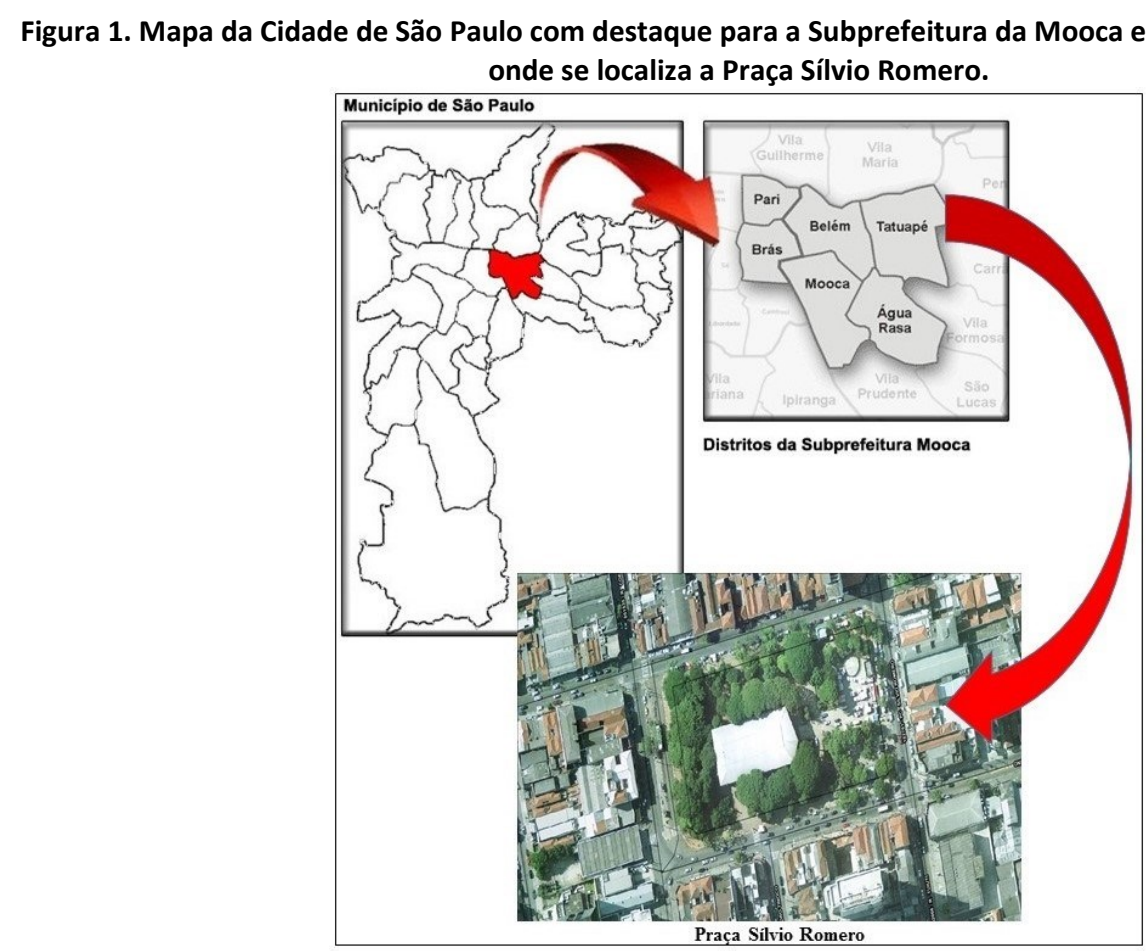

Fonte: Geomapas.

A Praça Sílvio Romero, fundada em 1931, leva este nome devido a uma homenagem prestada ao historiador e professor Sílvio Vasconcelos da Silveira Ramos Romero que participou da instalação da Academia Brasileira de Letras e foi o fundador da 17ํ cadeira acadêmica. $O$ então 
Sílvio Romero, como era chamado, também foi crítico literário e ingressou como Deputado Federal pelo Estado de Sergipe (ABL, 2016).

\section{COLETA E ANALISE DE DADOS}

Para o desenvolvimento desta pesquisa, os dados coletados foram baseados em fichas propostas por De Angelis et al. (2004), adaptado para a Praça Sílvio Romero, que permitiu avaliar as estruturas e equipamentos do local. As fichas foram preenchidas durante as visitas à Praça, que ocorreram entre novembro de 2015 e setembro de 2016.

Para identificar a percepção ambiental dos frequentadores da Praça, foram realizadas entrevistas, com 100 voluntários, baseadas em um roteiro semiestruturado (composto de perguntas abertas e fechadas) sobre a praça, além de questões que permitiram traçar o perfil desses indivíduos.

\section{RESULTADOS E DISCUSSÃO}

A coleta de dados sobre os equipamentos e infraestrutura da Praça Sílvio Romero demonstra que a Praça possui boa iluminação, alternando entre postes altos, localizados nos gramados centrais da praça (Tabela 1). Postes baixos rodeiam a pista de caminhada e a ciclovia que fica em frente a Igreja Nossa Senhora da Conceição, localizada no centro da Praça. Além disso, a Praça dispõe de lixeiras, obras de arte, ponto de ônibus, ponto de taxi, banca de revistas, quiosques para alimentação, bancos e muitas espécies vegetais. Entretanto, não há bebedouros e sanitários, nem quadra esportiva e parque infantil.

Tabela 1. Levantamento quali-quantitativo dos equipamentos e estruturas existentes no Parque
\begin{tabular}{lccc}
\multicolumn{1}{c}{ EQUIPAMENTOS/ESTRUTURAS } & QUANTIDADE & QUALIDADE \\
\hline 1. Bancos - material: madeira e concreto & 148 & ÓTIMO \\
2. lluminação alta & 21 & ÓTIMO \\
3. lluminação baixa & 12 & ÓTIMO \\
4. Lixeiras & 25 & RUIM \\
5. Sanitários & 0 & - \\
6. Bebedouros & 0 & - \\
7. Caminhos - material: concreto & 3 & BOM \\
8. Obra de arte & 2 & PÉSSIMO \\
9. Ponto de ônibus & 1 & BOM \\
10. Ponto de táxi & 1 & REGULAR \\
11. Quadra esportiva & 0 & - \\
12. Parque infantil & 0 & - \\
13. Banca de revista & 3 & BOM \\
14. Quiosque de alimentação & 14 & ÓTIMO \\
15. Vegetação & 204 árvores & ÓTIMO \\
\hline
\end{tabular}

Fonte: Elaborada pela autora a partir dos dados coletados durante a realização deste estudo, 2015/2016.

Além dos 148 bancos encontrados na Praça (conforme figura 1), que são fixos e todos estão em bom estado de conservação, também há assentos móveis e estes podem mudar conforme a quantidade de pessoas no local, seja quando os frequentadores estão participando de algum evento ou somente comendo um lanche. Como observado na tabela 1, foram contabilizados 33 postes de iluminação, em toda área da Praça, destes 21 são de iluminação alta e 12 são de 


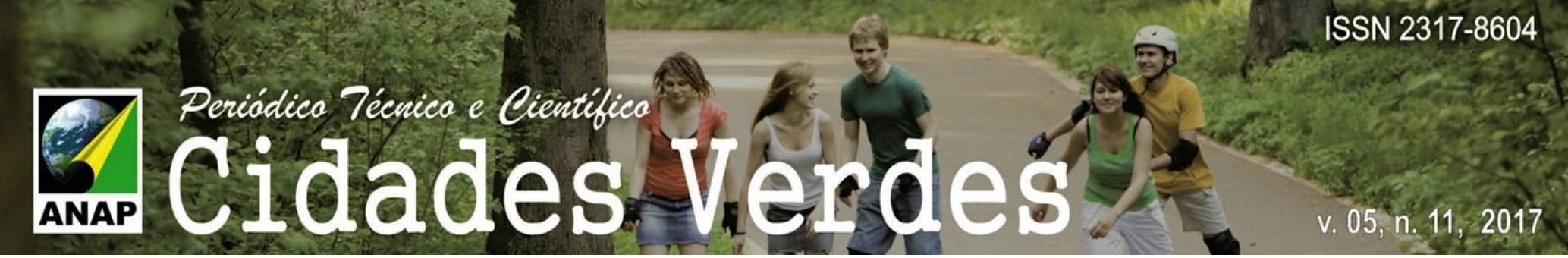

iluminação baixa. Os postes são classificados como postes de iluminação telefônicos retos, fabricados em tubos de aço.

Conforme demonstra a tabela 1, a praça conta com 25 lixeiras, destas 23 lixeiras são destinadas ao descarte de resíduos comuns não recicláveis, e 2 lixeiras são destinadas ao descarte de resíduos passíveis de reciclagem (coleta seletiva) onde os frequentadores da Praça podem separar os resíduos produzidos com: vidro; papel; metal e plástico. No que se refere ao item quadra esportiva, cabe mencionar que praça não comporta uma estrutura como essa, pois na área atrás da igreja há três comércios e no espaço à frente da igreja existe um estacionamento de bicicletas. Além disso, o espaço restante na praça geralmente é utilizado para eventos, como: feirinhas de artesanato e shows católicos promovidos pela Paróquia Nossa Senhora da Conceição. Na figura 2 é possível visualizar a Igreja, a vegetação e alguns equipamentos que compõem a Praça, bem como, alguns frequentadores e uma das ruas no entorno do local.

Figura 2. Praça Sílvio Romero. A - Vista da Matriz Paroquial Nossa Senhora da Conceição; B - Frequentadores da Praça e o monumento próximo ao sino; C - Vista lateral da Praça onde é possível alugar e devolver bicicletas; D Vista do lado esquerdo da Praça onde é possível observar alguns bancos, espécies vegetais e o gradil da igreja.

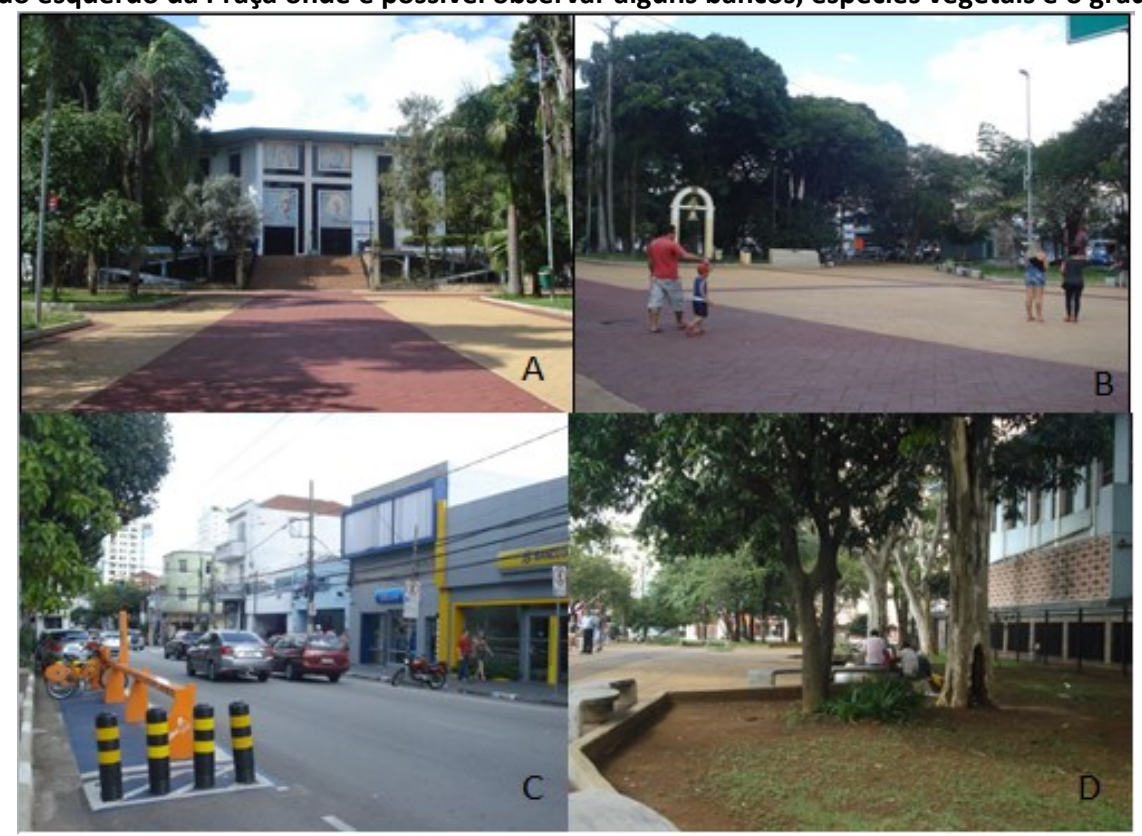

Fonte: Autores

A percepção dos frequentadores da Praça foi levantada a partir da realização de entrevistas com 100 voluntários. Os dados sobre o perfil dos respondentes demonstram que os frequentadores da Praça Sílvio têm em média 50 anos ou mais (33\%), seguida por 18 a 29 (31\%), 20 a 30 anos (20\%) e 40 a 49 anos (16\%), conforme tabela 2.

Quanto a escolaridade a maioria cursou o Ensino médio completo (52\%), Ensino superior completo (16\%), seguido de Ensino Superior incompleto (3\%) Ensino médio incompleto (10\%), ensino fundamental completo (10\%), ensino fundamental incompleto $(10 \%)$ e a Pós-graduação completa seguiram com (2\%). 
Tabela 2. Perfil dos frequentadores entrevistados da Praça Sílvio Romero em 2016.

\begin{tabular}{|c|c|c|}
\hline \multirow[t]{2}{*}{ VÁRIAVEIS } & \multicolumn{2}{|c|}{$\mathrm{N}=100$} \\
\hline & $\mathrm{N}=$ & $\%$ \\
\hline \multicolumn{3}{|l|}{ SEXO } \\
\hline Feminino & 39 & $39 \%$ \\
\hline Masculino & 61 & $61 \%$ \\
\hline \multicolumn{3}{|l|}{ FAIXA ETÁRIA } \\
\hline 18 a 29 anos & 31 & $31 \%$ \\
\hline 30 a 39 anos & 20 & $20 \%$ \\
\hline 40 a 49 anos & 16 & $16 \%$ \\
\hline 50 anos ou mais & 33 & $33 \%$ \\
\hline \multicolumn{3}{|l|}{ NIVEL DE ESCOLARIDADE } \\
\hline Ensino Fundamental Incompleto & 7 & $7 \%$ \\
\hline Ensino Fundamental Completo & 10 & $10 \%$ \\
\hline Ensino Médio Incompleto & 10 & $10 \%$ \\
\hline Ensino Médio Completo & 52 & $52 \%$ \\
\hline Ensino Superior Incompleto & 3 & $3 \%$ \\
\hline Ensino Superior Completo & 16 & $16 \%$ \\
\hline Pós Graduação Completa & 2 & $2 \%$ \\
\hline \multicolumn{3}{|l|}{ FREQUÊNCIA POR SEMANA } \\
\hline De 1 à 3 vezes & 46 & $46 \%$ \\
\hline Todos os dias & 28 & $28 \%$ \\
\hline Só aos finais de semana & 24 & $24 \%$ \\
\hline Raramente & 2 & $2 \%$ \\
\hline \multicolumn{3}{|l|}{ PERÍODO QUE FREQUENTA } \\
\hline Manhã & 59 & $59 \%$ \\
\hline Tarde & 34 & $34 \%$ \\
\hline Noite & 2 & $2 \%$ \\
\hline Mais de um período & 5 & $5 \%$ \\
\hline \multicolumn{3}{|l|}{ FÁCIL ACESSO } \\
\hline Sim & 96 & \\
\hline Não & 4 & \\
\hline \multicolumn{3}{|l|}{ MEIO DE TRANSPORTE UTILIZADO } \\
\hline A pé & 49 & $49 \%$ \\
\hline Carro & 14 & $14 \%$ \\
\hline Ônibus & 37 & $37 \%$ \\
\hline
\end{tabular}

Fonte: Elaborada pela autora a partir dos dados coletados durante a realização deste estudo, 2015/2016.

Conforme descrito na tabela 2, a maioria dos entrevistados costumam frequentar a Praça Sílvio Romero de 1 a 3 vezes por semana (46\%), seguidos pelos que frequentam só de finais de semana (24\%), todos os dias $(28 \%)$ e raramente (2\%). No quesito período, observar-se que os entrevistados frequentam a Praça mais durante a manhã (59\%), seguidos dos que preferem a tarde (34\%), mais de um período (5\%) e noite seguido de (2\%).

Sobre a percepção ambiental dos frequentadores da Praça Sílvio Romero, sobre a Praça, no quadro 1 é possível observar os posicionamentos topofílicos (sentimentos positivos em relação a praça) e topofóbico (sentimento negativo em relação a praça) dos entrevistados. Nota-se que, na percepção dos entrevistados, os aspectos topofílicos em relação à Praça Silvio Romero são: a possibilidade de ter contato com a natureza e com outras pessoas; ter um espaço para o lazer e descanso; a beleza desse espaço; a oferta de estruturas voltadas à alimentação; e a facilidade de acesso à Praça, inclusive utilizando o transporte público, como ônibus por exemplo. 
Quadro 1. Elementos topofílicos e topofóbicos da percepção de entrevistados que frequenta a Praça Silvio Romero, Zona Leste da cidade de São Paulo.

\begin{tabular}{|l|l|l|}
\hline \multicolumn{1}{|c|}{ 1) Para você como é a Praça Silvio Romero? } & \multicolumn{1}{|c|}{ 2) Como você descreveria esta praça a alguém que } \\
nunca a visitou?
\end{tabular}

Fonte: Elaborada pela autora a partir dos dados coletados durante a realização deste estudo, 2015/2016.

Quanto aos aspectos topofóbicos, na percepção dos entrevistados, a manutenção dos equipamentos, estruturas e da vegetação, e a higiene da Praça são precárias. Os entrevistados ressaltam a falta de brinquedos para as crianças, a falta de eventos, além da presença de pessoas em situação de rua, de dependentes químicos e de pessoas que não seguem as regras de conservação do espaço.

Identificar os sentimentos topofílicos e topofóbicos dos frequentadores de áreas verdes urbanas, como as praças e parques, possibilita o desenvolvimento de políticas de gestão baseadas nos desejos e anseios da população que usufrui desses espaços (RÉGIS et al., 2015). Oliveira et al. (2014) ressalta que é muito importante conhecer a opinião dos frequentadores das praças, e que essas informações devem ser usadas pelos gestores públicos na elaboração de projetos de gestão.

Ao que se refere a percepção dos frequentadores e, relação à função e contribuição das praças públicas, os resultados demonstram que, para os entrevistados, a responsabilidade pelo cuidado e preservação de praças não é só da prefeitura (57\%), mas da população que frequenta também (62\%), conforme descrito na tabela 3. Ainda na tabela 3, observa-se que a maioria dos entrevistados concordam que: praça é um local de troca de informações e 
convívio de adultos (92\%); praça é importante para deixar a cidade mais bonita (99\%); praça é um local adequado para crianças e adolescentes (93\%) e $82 \%$ dos entrevistados, concordam que praça é importante no resgate e manutenção de animais e plantas concordam.

Tabela 3. Percepção de frequentadores em relação à função e contribuição de praças públicas de acordo com assertivas e escala likert.

\begin{tabular}{lccc}
\multicolumn{1}{c}{ Assertivas } & CONCORDO & $\begin{array}{c}\text { NÃO CONCORDO E } \\
\text { NEM DISCORDO }\end{array}$ & DISCORDO \\
\hline Praças são locais de troca de informação e convívio de adultos. & $92 \%$ & $5 \%$ & $3 \%$ \\
\hline Praça é importante para deixar a cidade mais bonita. & $99 \%$ & - & $1 \%$ \\
Praça é importante no resgate e manutenção de animais e plantas. & $82 \%$ & $15 \%$ & $3 \%$ \\
Praça é um local adequado para crianças e adolescentes. & $93 \%$ & $3 \%$ & $4 \%$ \\
Praça é um local que contribui para melhor qualidade de vida & $90 \%$ & $7 \%$ & $3 \%$ \\
$\begin{array}{l}\text { A responsabilidade de cuidado e preservação da praça é da } \\
\text { prefeitura. }\end{array}$ & $57 \%$ & $24 \%$ & $19 \%$ \\
$\begin{array}{l}\text { A responsabilidade do cuidado e preservação da praça é da } \\
\text { população que frequenta a praça. }\end{array}$ & $62 \%$ & $22 \%$ & $16 \%$ \\
Praças contribuem para diminuir a poluição do ar. & $96 \%$ & $1 \%$ & $3 \%$ \\
\hline
\end{tabular}

Fonte: Elaborada pela autora a partir dos dados coletados durante a realização deste estudo, 2015/2016.

Ao que se refere à contribuição de praça na qualidade de vida, $90 \%$ dos entrevistados concordam com esta assertiva e $96 \%$ concordam que praças contribuem para diminuir a poluição do ar. Estes benefícios são citados por Albertin et al. (2011) que observam a melhoria na qualidade de vida gerada pela vegetação, por estabilizarem o clima, aumentarem a umidade do ar e diminuírem a temperatura. Além disso, o contato com a flora promove sensação de bem-estar aos frequentadores de praças.

Cabe mencionar que cada frequentador tem uma maneira particular de se relacionar com a natureza. De acordo com Tuan (2012), para compreender o olhar do indivíduo sobre determinada paisagem é preciso considerar o contexto e as "visões" que cada um tem de algo em particular. Para compreender como os entrevistados percebem as áreas verdes foi feita a seguinte pergunta: Quando se fala em áreas verdes quais as palavras que vem à sua cabeça? Conforme descrito no gráfico 1, a palavra que mais vêm à mente dos entrevistados é árvore (52\%), seguida de plantas (18\%), animais (16\%) e natureza (14\%).

Ao longo das entrevistas os frequentadores relataram que as árvores da Praça Sílvio Romero precisam de mais cuidados, que os canteiros estão maltratados e precisam de manutenção.

\section{CONCLUSÃO}

A Praça Silvio Romero apresenta boa infraestrutura para seus frequentadores tanto em quantidade de equipamentos quanto em qualidade. Os bancos, iluminação, quiosques e vegetação foram muito bem avaliados. No entanto as lixeiras da praça encontram-se em estados ruins de manutenção. Cabe mencionar que o espaço público não dispões de bebedouros, sanitários e playground, o que é muito valorizado por frequentadores.

Os frequentadores percebem e interagem de forma positiva com a Praça Sílvio Romero. É possível inferir que a percepção dos entrevistados em relação a Praça está realmente baseada 
nas experiências e interações estabelecidas com esse espaço, pois esses indivíduos também relataram aspectos negativos e a necessidade de melhorias no local.

Tais aspectos podem ser usados como uma ferramenta de formulação de estratégias de gestão para a Praça Sílvio Romero, baseadas nos desejos e anseios da população que frequenta esse espaço de funções diversificadas, que também é o marco histórico da região onde está implantada, visto que após o surgimento da praça a localidade passou a ser um lugar de encontro e referência no Bairro do Tatuapé na Cidade de São Paulo.

\section{REFERÊNCIAS BIBLIOGRÁFICAS}

ABL - Academia Brasileira de Letras. Disponível em: <

http://www.academia.org.br/academicos/silvio-romero/biografia > Visualizado em 08/08/2016.

ALBERTIN, Ricardo Massulo et al. Diagnóstico quali-quantitativo da arborização viária de Nova

Esperança, Paraná, Brasil. Revista da Sociedade Brasileira de Arborização Urbana. 2011; 6 (3): 128-148.

BENCHIMOL, Juliana Furlaneto et al. Decentralized management of public squares in the city of São

Paulo, Brazil: Implications for urban green spaces. Land Use Policy, v. 63, p. 418-427, 2017.

COSTA, R. G. S.; COLESANTI, M. M. A contribuição da percepção ambiental nos estudos das áreas verdes. Raega. $O$ espaço geográfico em análise, 22, 2011.

DE ANGELIS, Bruno Luiz Domingos et al. Metodologia para levantamento, cadastramento, diagnóstico e avaliação de praças no Brasil. Maringá, Paraná. Engenharia Civil, v.4, n.1, p. 57-70, 2004.

FERNANDES, R. S., SOUZA, V. D., PELISSARI, V. B., \& FERNANDES, S. T. Uso da percepção ambiental como instrumento de gestão em aplicações ligadas à área educacional, social e ambiental. Encontro Nacional de Pós-graduação em Pesquisa ambiente e Sociedade, 2,1-15, 2004.

HOUAISS, Antônio. Dicionário da Língua Portuguesa. Adaptado à reforma ortográfica. 3.a edição. Rio de Janeiro. Objetiva, 2008.

IBGE - Instituto Brasileiro de Geografia e Estatística. Censo de 2010.

LIMA, Luiz Felipe Bedore et al. Estruturas e equipamentos de praças públicas do município de Nova Luzitânia, SP. Trabalho acadêmico. Eixo temático: Cidades verdes. ANAP. 2015.

MORERO, M. ANDREA. SANTOS, F. ROZELY. FIDALGO, C.C. ELAINE. Planejamento ambiental de áreas verdes: Estudo de caso em Campinas- SP. Dissertação de Mestrado. UNICAMP, Campinas - SP. Rev. Inst. Flor. São Paulo, v.19,n.1, p. 19-30, jun.2007.

OLIVEIRA, Kelly Chaves et al. Levantamento quali-quantitativo de equipamentos e estrutura de cinco praças na cidade de São Paulo, SP. Artigo Acadêmico. ANAP. Associação Amigos da Natureza. SP. 2014.

PEREIRA, Érico Felden; TEIXEIRA, Clarissa Stefani; SANTOS, Anderlei dos. Qualidade de vida: abordagens, conceitos e avaliação. Rev. bras. educ. fís. esporte, São Paulo, v. 26, n. 2, p. 241-250, June 2012.

RÉGIS, Milena de Moura et al. Relato Técnico: percepção de frequentadores sobre o espaço, estrutura e gestão do Parque da Água Branca, SP. Periódico Técnico e Científico Cidades Verdes, 3(6),2015.

RICKLEFS, Robert E. A economia da natureza. Rio de Janeiro, Guanabara Koogan, 2011. 


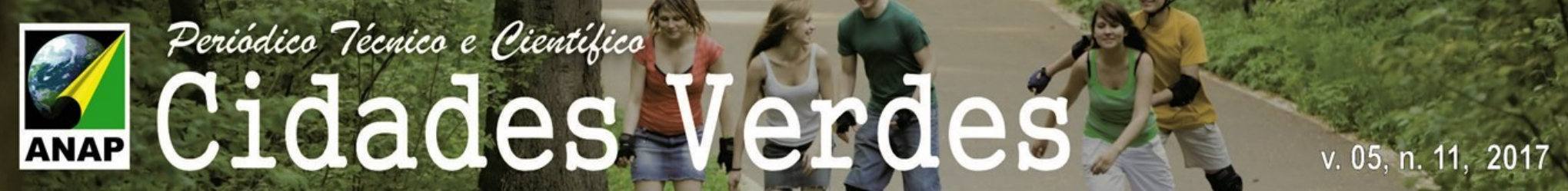

ROBBA, Fábio; MACEDO, Silvio Soares. Praças Brasileiras. São Paulo: Editora da Universidade de São Paulo. 2002.

SVMA - Secretaria Municipal do Verde e do Meio Ambiente. Manual técnico de arborização urbana. Prefeitura de São Paulo. 2.a Edição. São Paulo, 2005.

SUESS, Rodrigo Capelle et al. Percepção ambiental de diferentes atores sociais sobre o Lago do Abreu em Formosa. Go. Holos, v.6, p. 241-258, 2013.

TUAN, Yi-Fu. Topofilia: um estudo da percepção, atitudes e valores do meio ambiente. Londrina: EDUEL, 2012.

ZILLER, Silvia Renati. Árvores exóticas e nativas. Ciência hoje. Dez 2001. 